\title{
Student experience of using mobile devices for learning chemistry
}

\author{
Wai Foong Lok ${ }^{1}$, Mahizer Hamzah ${ }^{2}$ \\ ${ }^{1}$ Department of Science, Perak Matriculation College, Malaysia \\ ${ }^{2}$ Department of Educational Studies, Faculty of Human Development, Universiti Pendidikan Sultan Idris, Malaysia
}

\begin{tabular}{|c|c|}
\hline Article Info & ABSTRACT \\
\hline Article history: & \multirow{10}{*}{$\begin{array}{l}\text { Mobile devices have been utilized as an emerging learning tool in the } 21 \mathrm{st} \\
\text { century to support the learning of chemistry. This study aimed to identify } \\
\text { matriculation students' learning experience with regards to the use of mobile } \\
\text { devices for learning chemistry. The study employed a qualitative case study } \\
\text { approach, which was carried out in a matriculation college. Online diaries } \\
\text { and interviews were utilized as the instruments of the study. A total of } 84 \\
\text { students initially reflected their learning journey using an online diary, } \\
\text { whereas } 17 \text { students who were active in mobile learning were purposely } \\
\text { selected for the interview. The findings revealed that students have positive } \\
\text { and negative experiences towards the use of mobile devices for learning } \\
\text { chemistry. They positively perceived that using a mobile device for learning } \\
\text { chemistry promotes knowledge construction, visualization of abstract } \\
\text { concepts, self-control in learning and intellectual discourse. However, the } \\
\text { issue of learning resources quality challenged their available cognitive } \\
\text { capacity for learning chemistry. This study offered educators with insights } \\
\text { about the importance of incorporating mobile devices for learning chemistry. } \\
\text { Educators can plan the appropriate instructional strategies for chemistry } \\
\text { based on the students' learning needs. }\end{array}$} \\
\hline Received Jan 1, 2021 & \\
\hline Revised Jun 24, 2021 & \\
\hline Accepted Jul 12, 2021 & \\
\hline Keywords: & \\
\hline Chemistry & \\
\hline Experiences & \\
\hline Learning & \\
\hline Mobile devices & \\
\hline Mobile learning & \\
\hline
\end{tabular}

This is an open access article under the CC BY-SA license.

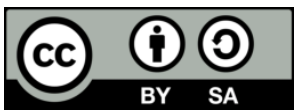

Corresponding Author:

Wai Foong Lok

Department of Science, Perak Matriculation College

Ministry of Education

31600 Gopeng, Perak, Malaysia

Email: drlokwf@gmail.com

\section{INTRODUCTION}

Parallel to the growing global interest in Science, Technology, Engineering, And Mathematics (STEM) education to enhance economic prosperity via a highly-educated workforce, the implementation of STEM education is strengthened in the Malaysian education system through the Malaysia Education Blueprint 2013-2025 [1]. STEM education is a teaching and learning discipline where Science, Technology, Engineering, and Mathematics are taught in an integrated manner, so that students are able to apply the knowledge, skills and values of these subjects to solve real-world problems [2], [3].

Chemistry is among the STEM subjects that is taught in the upper secondary and pre-university levels in Malaysia. However, students always negatively perceived that learning chemistry requires the skill of memorizing abstract facts and concepts, and involves the solving of difficult numerical problems and understanding the complicated principles of chemistry [4]-[7]. Moreover, students are unable to apply the scientific theories and ideas learned to their everyday lives, due to less emphasis in using information and computer technology (ICT) to make STEM learning more engaging. The learning approaches for STEM 
subjects are criticized as teacher-centered, and are focused on preparing students for examination, which will eventually provide limited space for students to be critical, creative and innovative in learning [2].

As such, interesting, meaningful and challenging learning approaches are highly recommended to strengthen STEM education, particularly in chemistry learning [8]. A variety of teaching and learning approaches have been adopted in STEM education to promote students' engagement and achievement, such as inquiry-based, project-based, problem-based, argumentation and reasoning, gamification, and digital learning approaches [2], [9]. These learning approaches have been applied to promote students' learning through creative and critical thinking, and incorporate meaningful and reasoning processes in a collaborative learning environment [9].

Among these current learning approaches in STEM education, Grimus and Ebner [10] state that mobile learning is a perfectly matched learning approach for STEM subjects. This is because the primary focus of STEM education is on real-world authentic problems, whereas mobile learning is dedicated to activity-oriented use in practice [10]. Moreover, Bidarra and Rusman [11] argue that instead of engaging students in authentic learning activities in STEM subjects, mobile learning is used to promote learning beyond the traditional view of "classroom instructions". Learning, in the context of STEM education, should be an on-going process that enables the continued exploration, participation and negotiation in various circumstances, roles and environments [11].

The majority of researchers define mobile learning as a form of learning delivered by handheld mobile technologies [12]. However, Borba, et al. [13] denote that mobile technologies are used to facilitate learning, regardless of place, by the development of the intertwined interaction among people, content and devices. Recent studies indicate that the use of mobile technology in learning offers great opportunities for students to improve learning experiences [14]-[16]. It is a versatile educational tool that facilitates flexibility, collaboration, individualization, personalization and interactivity in learning [17]-[19]. Nonetheless, students' experience with regards to the use of mobile devices in learning has led to mixed results. Studies have shown that the limitations of mobile devices and technologies might affect the overall quality of learning. These limitations included small keypad and screen size, short battery life, inadequate memory or storage capacity and poor Internet bandwidth [18], [20]. In addition, Qureshi, et al. [21] argued that mobile phones are more applicable for language learning due to the ability to send videos and images through mobile phones, and the effectiveness of mobile applications (apps) to support language learning.

Despite these advantages and disadvantages, mobile learning has been recognized as an emergent technological tool that is best suited for chemistry learning in the 21 st century. This is due the fact that mobile learning has associated the cognitive, sociocultural and motivational aspects of learning, in order to improve students' knowledge, skills and values in chemistry [22]. Previous studies have indicated the integration of multimedia, computer simulations, electronic resources, social networking sites and educational games in mobile learning, support the teaching and learning of chemistry [23]. The incorporation of these instructional strategies in mobile learning for chemistry is supported by several learning theories, including constructivism, social constructivism and cognitive theory of multimedia learning [24], [25].

Therefore, mobile devices such as smartphones and tablets have been currently utilized as an emergent teaching and learning tool to transform traditional chemistry teaching and learning methods into a more sustainable 21 st century teaching and learning approach [22]. To date, the majority of mobile learning studies have focused on investigating the use of mobile devices and technologies themselves [26]. Nevertheless, the adoption of mobile devices in both formal and informal learning for STEM subjects, especially for chemistry at a pre-university level, namely, a matriculation program, remains to be underresearched [27]. This study aims to identify matriculation students' experience with regards to the use of mobile devices for learning chemistry. The findings of this study can provide insight on students' needs for learning chemistry, in order to examine the potential of incorporating a mobile learning approach in chemistry for matriculation programs in Malaysia.

\section{RESEARCH METHOD}

In order to identify matriculation students' experience with regards to the use of mobile devices for learning chemistry, a qualitative case study approach was employed. Qualitative case study adopted an interpretive approach to understand the meaning constructed by individuals or groups with regard to a phenomenon in a real-life setting [28], [29]. A mathematical proof of what occurred during the mobile learning intervention, such as survey, was unable to provide thick description about a phenomenon in natural setting [30]. Nevertheless, collecting and analyzing data qualitatively in the field could provide a dynamic and comprehensive view of the specifically matriculation students' experience in this study [31].

This study was carried out in a matriculation college located in the northern part of Peninsular Malaysia. The data collection consisted of two phases. During the first phase of data collection, 84 students 
agreed to participate and record their learning experiences in an online journal or diary. Some pre-requisite criteria were used as a filtering mechanism, such as selecting only those who have Internet-enabled smartphone and personal mobile data plan to perform learning using mobile device. Thereafter, this was reduced to only 17 who were found to be active in using mobile devices for learning at the end of the first phase of data collection. It was determined based on the number of entries written in their individual online journal or diary. These students were then purposely invited for the second phase of data collection, namely, the face-to-face interviews.

Interviews and online journals or diaries were the two main instruments used in this study. A semistructured journal was developed to enable the students to reflect and record their learning journey. It consisted of a series of open-ended questions that were deemed suitable in this study to inductively uncover their views regarding the of use mobile devices for learning chemistry. Meanwhile, the semi-structured interview was guided by several open-ended questions to elicit students' descriptions about their experience in using mobile devices for learning chemistry. The interview protocol was prepared in both English and Malay. As such, the participants were able to choose which language they preferred for the face-to-face interview session. It was to ensure the accuracy and clarity of the information being shared by the language of their own preference [32]. Both instruments were reviewed and checked by experts who have vast experience in qualitative research, and were familiar with the use of instructional technology in mobile learning.

In terms of data analysis, students' responses in their online diary and from the interviews were transcribed into verbatim transcripts. All the data were then analyzed based on the method suggested by Graneheim and Lundman [33], which involved transcription, condensation, abstraction, and categorization, to identify the emerging themes regarding students' learning experiences of using mobile devices for learning chemistry. Additionally, member checking, data triangulation and interrater reliability assessment were adopted to enhance the overall validity and reliability of the qualitative data obtained in the study. For example, some transcribed interviews were returned back to the respective students for checking their accuracy. It was to ensure that the students' opinions were not misinterpreted [34] and the conclusions reached were accurately represented their actual views [28]. Data triangulation was another method to enhance validity of the study [35]. As such, the data were triangulated by comparing interview data with the entries written in students' online diary. In order to increase the level of agreement between coded data, the researchers engaged in an interrater reliability process. Each researcher used to code independently several interview transcripts, and to look on the percent agreement using kappa score. The Cohen's kappa value of 0.769 indicated that there was substantial agreement among the raters [36], and thus it suggested that a consistent interpretation of the data have been performed in this study.

\section{RESULTS AND DISCUSSION}

The students' learning experiences on the use of mobile devices for chemistry were analyzed and categorized into six themes, namely: 1) Constructing knowledge; 2) Visualizing abstract concepts; 3) Selfcontrol in learning; 4) Novelty in learning; 5) Discoursing of ideas; and 6) Quality of learning resources.

\subsection{Constructing knowledge}

Students revealed that they used to construct and acquire knowledge in chemistry individually, based on the learning resources obtained using mobile devices. The individual knowledge construction and acquisition processes were enhanced by the guidance provided, such as the in-depth and step-by-step explanations, and animated and authentic examples. Student 8 stated the following in the interview and diary.

"I like the video that the people upload in the YouTube. This is my main source of information. They really help. Because they explain what they do, why they do it, everything." (Interview)

"The best thing is the simple explanation given. Really help." (Diary)

Moreover, the construction of knowledge in chemistry was developed by their active participation during the learning process, in which they needed to explore and interpret the learning resources, either by using their own judgment, or by obtaining advice from their lecturers or peers. Student 1 adopted several methods to interpret and select the most appropriate chemistry learning resources.

"Sometime is not easy. I can't get the resources that I really want in the Internet. I need to search carefully. Looking for other websites and compare. Sometimes, I need to refer what the lecturer has taught, then could I able to answer the question." (Interview) 
This finding is explained by the constructivist learning theory, which is a contemporary theoretical foundation that depicts that students constructed their own knowledge by learning from books, online resources or teachers. Learners used to construct their overall understanding of knowledge and form new cognition through their own experience [37]. Due to the abstractness of the concepts in chemistry, such as atomic structure, learning resources that are guided with animated illustrations are essential to enhance students' understanding [38]. Students would be able to connect and represent three conceptual levels in chemistry, namely, macroscopic, submicroscopic, and symbolic levels, to better attain abstract concepts in chemistry [7].

\subsection{Visualizing abstract concepts}

Most students in this study admitted that they could easily understand the abstract concepts in chemistry via the animated presentations using their mobile devices. The students were pleased with the affordance of mobile devices to provide in-depth explanations on abstract concepts by using 3D animations and multimedia videos. Student 9 explained the effect of animation in visualizing abstract chemistry concepts.

"We need imagination in chemistry. For example, how the electron is formed, how it moves. For some people, they might not able to imagine how it moves. So, video shows us the simulation of how electron moves. It is something really... really real..." (Interview)

"I could imagine how electron is moving when observing in video." (Diary)

This finding revealed the importance of animations and multimedia in video to support students' learning in chemistry. Putra, et al. [39] stated that android-based chemistry learning media in the form of multimedia could attract students' interests in learning chemistry. Abstract chemistry concepts are best viewed using visual representations with the aid of modern technology, such as multimedia and animated video [6], [39]. Animation helps to illustrate the chemical phenomena at the submicroscopic level, and to relate it to different symbolic representations of concepts in chemistry [40].

Shroff, et al. [24] indicated that the use of mobile technologies such as mobile applications supported the constructivist learning opportunity, which provides discovery and imaginative thinking via multimedia instruction. The aid of multimedia presentations enables knowledge such as abstract chemistry concepts to be appropriately organized to facilitate students' meaning-making ability.

\subsection{Self-control in learning}

The majority of the students indicated the affordance of mobile devices to take control over their learning of chemistry. They commented about the affordance of learning at their own pace when mobile devices were used for learning chemistry. They could retrieve learning resources in mobile devices based on their needs. Student 2 mentioned the following:

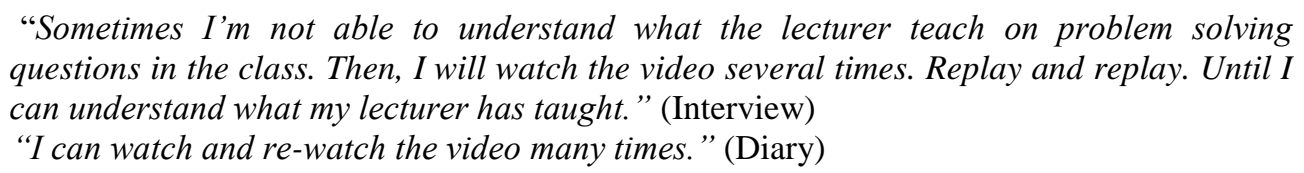

This implies that students were pleased by the affordance of mobile devices for allowing greater freedom and control towards their learning. As such, the use of mobile devices could be directed towards self-regulated learning and increase their understanding to the particular competence [40]. Students could flexibly determine their learning objectives, plan their learning activities and monitor their progress of learning [41]. Alternatively, self-control in learning for chemistry provides the time and opportunity for students to reflect and internalize the information in chemistry [42]. Constructivism suggests that students' conceptual understanding could be enhanced when they constantly applied explicit thinking, reasoning, and reflective meta-cognitive skills in learning [40].

\subsection{Novelty in learning}

Students in this study also claimed that the use of mobile devices was a new learning approach for learning chemistry. They have mentioned the use of a variety types of mobile apps for learning chemistry, such as molecular viewer apps, study guides and reference apps, structure drawing apps, and periodic table apps. They enjoyed using mobile apps for searching information on chemistry, instead of searching in thick chemistry textbooks. Students 7 and 12 mentioned the following: 
“Mainly if I want to refer Periodic Table, I got download one app." (Student 7, Interview)

"For some information such as periodic table... Later, I need not open my book, just on my phone and look for it." (Student 12, Interview)

This novelty in learning has transformed the mode of learning among students for learning chemistry from heavily depending on printed-form information in textbooks, to auto-updated information on the Internet. Chemistry apps are powerful and compact tools to solve problems conveniently, with the reduced burden from conventional media, heavy books, and bulky computers [43]. The integration of mobile technology in learning supports the delivery of educational materials, which is unstructured, on-demand and timely [44]. Meanwhile, introducing a new learning tool and method may potentially increase students' interest in learning, as compared to traditional learning methods which are considered dull and boring [45].

\subsection{Discoursing of ideas}

Intellectual discourse was another type of learning experience indicated by the students throughout their learning process. They pointed out that discourse of ideas could be easily conducted with other fellow students via mobile devices, regardless of place and time. It also occurred between students and lecturers, in which the lecturers shared self-recorded videos as supplementary learning resources. The following excerpts supported this finding:

"If I can't solve the questions given or having problem in learning, or my friend(s) have problem, we will discuss it. Snap the answer and share it into the WhatsApp group. Discussing how to get the answer." (Student 14, Interview)

"Our lecturer likes to upload video(s) for us. Sometimes, she will send us the link of the video(s).” (Student 8, Interview)

Discourse is crucial in learning science subjects. It is in line to the central tenet of social constructivism that human action is mediated by tools of artifacts in the form of language. Language plays a significant role in thinking and learning, since learners internalize the it to structure their thinking [46]. Classroom discourse encourages students to internalize their learning before they explain scientific events using their own words [6]. It also enables lecturers to identify and correct students' misconceptions in chemical concepts [6]. As such, discourse of ideas indicates the existence of active knowledge construction in the learning process. In this study, mobile devices offer an alternative platform for discoursing ideas between students and other students or lecturers. However, the effectiveness of discoursing ideas for chemistry in a mobile learning environment has yet to be elaborated by the students who have participated in this study.

\subsection{Quality of learning resources}

A number of students mentioned the quality of learning resources as a possible distraction might affect their learning in chemistry. They felt distracted and frustrated when they were not able to understand the learning resources obtained from the Internet. These difficulties included the quality of the learning resources obtained, the use of complicated chemistry scientific terms, and the language or dialect spoken by the instructors on YouTube videos. Thus, this affected their interest and motivation in learning chemistry. The following excerpts clarify this finding:

"Video that I have found is sometimes too complicated. The text shown... the language that they used. I need to watch several times to understand it. I think it's better to ask the lecturer." (Student 3, Interview)

"Sometimes in the YouTube, it's quite difficult to understand. The explanation is too fast... and some explanation is confusing." (Student 10, Interview)

Despite of the popularity of digital technologies such as multimedia, to support number of learning opportunities in a mobile learning environment, it might challenge learners' available cognitive capacity [41]. The design of instructional strategies such as the integration of multimedia in chemistry learning will eventually affect students' meaningful learning in chemistry. The learning resources should be adequately designed so as to avoid exceeding students limited cognitive load [47], [48]. Yet, the frustration towards the quality of learning resources among the students who participated in this study might be associated to the unstructured digital learning environment. Thus, students should be guided and trained to effectively use educational contents in a mobile learning environment [49]. 


\section{CONCLUSION}

The findings of this study reveal that students have positive and negative experiences towards the use of mobile devices for learning chemistry. They were keen to use mobile devices for learning chemistry, since they promote knowledge construction, visualization of abstract concepts, self-control in learning, and intellectual discourse. The novelty effect brought by mobile devices could further increase students' interest in learning, especially in chemistry subject which encompassed a lot of abstract concepts. Meanwhile, the quality of learning resources, such as the improper design of learning materials, was a potential threat that might distract students' learning in chemistry. Despite the previous studies claimed that mobile devices are more applicable for language learning, the findings of this study suggest that the mobile devices can play a constructive role in facilitating students' learning in chemistry. The effect of digital technologies supported in mobile devices, such as 3D animation and multimedia in video, are able to enhance students' understanding on abstract chemistry concepts. Additionally, the interaction between students and other students or lecturers via mobile devices is advantageous mostly in terms of discoursing ideas based on the tenet of social constructivism. This new understanding shed light on the potential use of mobile devices to facilitate students' learning in chemistry. It also gives a better understanding of the matriculation students' learning practice and perception towards the use of mobile devices for chemistry.

Therefore, several recommendations are made based on the findings of this study. Firstly, the study inspires the lecturers in the matriculation college to revise their teaching approaches for chemistry based on students' learning needs. It implies that digital technologies should be integrated in their teaching approaches due the affordances of mobile device to facilitate learning in chemistry. Secondly, the inseparable from mobile devices amongst students born in the 2000s inspires the educators in the matriculation college to make mobile device as an intellectual discoursing tool for 21 st century chemistry learning medium. Thirdly, the study calls upon the management of matriculation college to revise the ICT policy in related to the use of mobile devices in education, especially in STEM subjects. The lecturers' training and professionalism workshops are necessary to make them competent and confident, in both knowledge and technical level, in implementing mobile learning.

There are several limitations in this study, which should be highlighted. This study was conducted in one matriculation college with limited number of participants. The future study could examine the perceptions of more students from different matriculation colleges. On the other hand, this study did not examine the effect of the use of mobile devices on students' chemistry learning performance. Therefore, an experimental study on the use of mobile devices will provide further insights about the effect of using mobile devices in students' chemistry learning performance. Another limitation is related to the lecturers' perception in using mobile devices for learning chemistry. In fact, lecturers are the key stakeholder in the implementation of mobile learning in educational institutions. The exploration of lecturers' possible resistances and obstacles to use mobile devices for their teaching practices, could develop a comprehensive view about mobile learning adoption in teaching and learning.

In summary, this study can conclude that promising learning experiences are developed among the matriculation students in using mobile devices for learning chemistry. This should be a boost for the matriculation lecturers to incorporate mobile devices in the teaching and learning for chemistry and other STEM subjects. The findings of this study strongly suggest that mobile device is an effective and attractive tool for learning chemistry in the 21 st century.

\section{ACKNOWLEDGEMENTS}

The authors acknowledge to the Perak Matriculation College for granting permission to conduct this study. Dedication also granted to the experts for their assistance in the stage of data analysis, and all students who have participated in this study.

\section{REFERENCES}

[1] Ministry of Education, Malaysia Education Blueprint 2013-2025 (Preschool to post-secondary education). Putrajaya, Malaysia: Kementerian Pendidikan Malaysia, 2013.

[2] E. H. M. Shahali, I. Ismail, and L. Halim, "STEM education in Malaysia: Policy, trajectories and initiatives," Asian Research Policy, vol. 8, no. 2, pp. 122-133, 2017.

[3] N. F. Ramli and O. Talib, "Can education institution implement STEM? From Malaysian teachers' view," International Journal of Academic Research in Business and Social Sciences, vol. 7, no. 3, pp. 721-732, 2017.

[4] N. F. Kamaruddin, N. H. Ibrahim, J. Surif, M. Ali, C. A. Talib, and N. 1. Ismail, "Malaysian science stream students' anxiety towards chemistry at the secondary school level," International Journal of Recent Technology and Engineering, vol. 7, pp. 724-738, 2019. 
[5] B. Bio, I. N. Suardana, and I. M. Kirna, "Analysis of learning difficulties of senior high school students in learning atomic structure," e-Journal Kimia Visvitalis Universitas Pendidikan Ganesha, vol. 2, no. 1, pp. 107-116, 2014.

[6] N. J. Ahmad, N. A. Ishak, and M. A. H. Bunyamin, "Learning demand and classroom discourse design tools to improve students' conceptual understanding of the nature of electrolytes," Asia Pacific Journal of Educators and Education, vol. 34, pp. 187-218, 2019.

[7] A. Wiyarsi, H. Sutrisno, and E. Rohaeti, "The effect of multiple representation approach on students' creative thinking skills: A case of 'Rate of Reaction' topic," Journal of Physics: Conference Series, vol. 1097, 2018, doi: 10.1088/1742-6596/1097/1/012054.

[8] Ministry of Education, Malaysia Education Blueprint 2013-2025: Annual report 2016. Putrajaya, Malaysia: Kementerian Pendidikan Malaysia, 2017.

[9] C. V. McDonald, "STEM Education: A review of the contribution of the disciplines of science, technology, engineering and mathematics," Science Education International, vol. 27, no. 4, pp. 530-569, 2016.

[10] M. Grimus and M. Ebner, "Mobile learning and STEM: First experiences in a senior high school in Ghana," in H. Crompton and J. Traxler, Eds., Mobile learning and STEM: Case studies in practice. New York: Routledge, 2016, pp. 1-16.

[11] J. Bidarra and E. Rusman, "Towards a pedagogical model for science education: Bridging educational contexts through a blended learning approach," Open Learning, vol. 32, no. 1, pp. 6-20, 2017.

[12] S. R. Sobral, "Mobile learning in higher education: A bibliometric review," International Journal of Interactive Mobile Technologies, vol. 14, no. 11, pp. 153-170, 2020.

[13] M. C. Borba, P. Askar, J. Engelbrecht, G. Gadanidis, S. Llinares, and M. S. Aguilar, "Blended learning, e-learning and mobile learning in mathematics education," ZDM Mathematics Education, vol. 48, pp. 589-610, 2016.

[14] K. Demir and E. Akpinar, "The effect of mobile learning applications on students' academic achievement and attitudes toward mobile learning," Malaysian Online Journal of Educational Technology, vol. 6, no. 2, pp. 48-59, 2018.

[15] G. J. Hwang and H. F. Chang, "A formative assessment-based mobile learning approach to improving the learning attitudes and achievements of students," Computers and Education, vol. 56, no.4, pp. 1023-1031, 2011.

[16] B. Oberer and A. Erkollar, "Mobile learning in higher education: A marketing course design project in Austria," Procedia-Social and Behavioral Sciences, vol. 93, pp. 2125-2129, 2013.

[17] R. O. A. Haliem, "Mobile ESL apps and students motivation: A case study," in European Conference on Language Learning, Brighton, United Kingdom, 2018.

[18] A. K. Mohammed and S. Lawal, "Student's perceptions on mobile learning," International Journal of Computer Science and Mobile Computing, vol. 7, no. 11, pp. 8-19, 2018.

[19] A. A. Mulhem, "Exploring the key factors in the use of an e-learning system among students at King Faisal University, Saudi Arabia," International Journal of Interactive Mobile Technologies, vol. 14, no. 3, pp. 19-36, 2020.

[20] A. Al-Hunaiyyan, R. A. Alhajri, and S. Al-Sharhan, "Perceptions and challenges of mobile learning in Kuwait," Journal of King Saud University- Computer and Information Sciences, vol. 30, pp. 279-289, 2018.

[21] M. I. Qureshi, N. Khan, S. M. A. H. Gillani, and H. Raza, "A systematic review of past decade of mobile learning: What we learned and where to go," International Journal of Interactive Mobile Technologies, vol. 14, no. 6, pp. 67-81, 2020.

[22] A.-N. Lay and K. Osman, "Developing 21st century chemistry learning through designing digital games," Journal of Education in Science, Environment and Health, vol. 4, no. 1, pp. 81-92, 2018.

[23] M. G. Ianos and G. C. Oproiu, "Using technology to teach chemistry. A theoretical approach," in the 14th International Scientific Conference eLearning and Software for Education, Bucharest, Romania, 2018, pp. 55-62.

[24] R. H. Shroff, C. Keyes, and W. Linger, "A proposed taxonomy of theoretical and pedagogical perspectives of mobile applications to support ubiquitous learning," Ubiquitous Learning: An International Journal, vol. 8, no. 4, pp. 23-44, 2015.

[25] D. Sulisworo and M. Toifur, "The role of mobile learning on the learning environment shifting at high school in Indonesia," International Journal of Mobile Learning and Organisation, vol. 10, no. 3, pp. 159-170, 2016.

[26] S. F. Ng, N. S. I. C. Hassan, N. H. M. Nor, and N. A. A. Malek, "The relationship between smartphone use and academic performance: A case of students in a Malaysian tertiary institution," Malaysian Online Journal of Educational Technology, vol. 5, no. 4, pp. 58-70, 2017.

[27] N. M. Nordin, M. A. Embi, H. Norman, and E. Panah, "A historical review of mobile learning research in Malaysia and its implications for Malaysia and the Asia-Pacific region," in Mobile learning in higher education in the AsiaPacific Region. Singapore: Springer, 2017, pp. 137-150.

[28] J. W. Creswell, Qualitative inquiry and research design: Choosing among five approaches, 3rd ed. Thousand Oaks, CA: SAGE Publications, 2013.

[29] R. K. Yin, Case study research: Design and methods, 5th ed. Thousand Oaks, CA: SAGE Publications, 2014.

[30] A. A. Ziden, M. Rosli, T. Gunasegaran, and S. N. Azizan, "Perceptions and experience in mobile learning via SMS: A case study of distance education students in a Malaysian Public University," International Journal of Interactive Mobile Technologies, vol. 11, no. 1, pp. 116-132, 2017.

[31] M. Q. Patton, Qualitative research and evaluation methods. Thousand Oaks, CA: SAGE Publications, 2015.

[32] A. R. Ibrahim, N. M. R. N. Yusoff, Z. Zakaria, A. B. A. Hilmi, and M. Spawi, "Teaching foreign languages to gifted and talented students using tablets," Journal of Global Business and Social Entrepreneurship, vol. 1, no. 4, pp. 112-122, 2017. 
[33] U. H. Graneheim and B. Lundman, "Qualitative content analysis in nursing research: Concepts, procedures and measures to achieve trustworthiness," Nurse Education Today, vol. 24, pp. 105-112, 2004.

[34] J. A. Maxwell, Qualitative research design: An interactive approach. Thousand Oaks, CA: SAGE Publications, 2005.

[35] P. I. Fusch and L. R. Ness, "Are we there yet? Data saturation in qualitative research," The Qualitative Report, vol. 20, no. 9, pp. 1408-1416, 2015.

[36] J. Cohen, "Kappa test: A coefficient of agreement for nominal scales," Educational and Psychological Measurement, vol. 20, no. 1, pp. 37-47, 1960.

[37] L. Zhang, X. Li, J. Wang, X. Ma, and M. Xu, "Construction of mobile teaching model based on connectivism learning theory in cloud environment," Journal of Computers, vol. 28, no. 4, pp. 215-226, 2017.

[38] S. Akaygun, "Is the oxygen atom static or dynamic? The effect of generating animations on students' mental models of atomic structure," Chemistry Education Research and Practice, vol. 17, pp. 788-807, 2016.

[39] P. S. Putra, N. B. Asi, M. E. Anggraeni, and Karelius, "Development of android-based chemistry learning media for experimenting," Journal of Physics: Conference Series, vol. 1422, 2020.

[40] S. Sana, C. Adhikary, and K. N. Chattopadhyay, "Evolutionary paradigm shift in the instructional strategies of chemical concepts," Bhatter College Journal of Multidisciplinary Studies, vol. 8, no. 1, pp. 72-79, 2018.

[41] B. Curum and K. K. Khedo, "Cognitive load management in mobile learning systems: Principles and theories," Journal of Computers in Education, vol. 8, pp. 109-136, 2021.

[42] D. Parsons and K. MacCallum, "A learning theory rubric for evaluating mobile learning activities," International Journal of Online Pedagogy and Course Design, vol. 7, no. 4, pp. 24-38, 2017.

[43] D. Libman and L. Huang, "Chemistry on the go: Review of chemistry apps on smartphones," Journal of Chemical Education, vol. 90, pp. 320-325, 2013.

[44] H. F. El-Sofany and N. El-Haggar, "The effectiveness of using mobile learning techniques to improve learning outcomes in higher education," International Journal of Interactive Mobile Technologies, vol. 14, no. 8, pp. 4-17, 2020.

[45] L. C. H. Amelia, M. J. Z. Abidin, and J. S. Saibon, "The benefits and drawbacks of using tablet-based digital storytelling in vocabulary learning among Malaysian young English as a Second Language (ESL) learners," Asia Pacific Journal of Educators and Education, vol. 34, pp. 17-47, 2019.

[46] L. S. Vygotsky, Mind in society. Cambridge, MA: Harvard University Press, 1978.

[47] M. V. Alyushin and L. V. Kolobashkina, "Monitoring of the current status of students as a means of increasing the effectiveness of educational process," The Education and Science Journal, vol. 21, no. 2, pp. 176-197, 2019.

[48] H.-C. Chu, "Potential negative fffects of mobile learning on students' learning achievement and cognitive load: A format assessment perspective," Educational Technology and Society, vol. 17, no. 1, pp. 332-344, 2014.

[49] K. Zhampeissova, A. Gura, E. Vanina, and Z. Egorova, "Academic performance and cognitive load in mobile learning," International Journal of Interactive Mobile Technologies, vol. 14, no. 21, pp. 78-91, 2020. 